Background The Global Program in Occupational Health Practice (GPOHP) is a 400 hour, online, interactive program with 2 tracks in Health and Hygiene. GPOHP has trained 135 individuals from 85 different countries over 8 years.

Methods An online survey of course participants was administered to determine the value of this training and to guide future content and training methods.

Results $30 \%$ of the prior course participants from 19 countries responded. 68\% received company sponsorship for tuition, 19\% received scholarships and 13\% were self-funded. Respondents reported a significant increase in knowledge base, greater confidence in doing their jobs, clarity about where to seek the best resources, awareness of global standards, and how to execute specific activities including, incident (accident) investigation, noise monitoring, ergonomic assessment, return to work after injury/illness, and development of a worker screening program. A few described moving up in their careers because of this training. Several participants continue to share ideas and plans with their classmates across national boundaries.

Discussion Online training in $\mathrm{OH}$ is an important and apparently successful tool for training those without locally available courses. Asynchronous communication lowers expenses by reducing time off work and out-of-country. Hands on activities applied in their own work settings with feedback from experts were likely to be key in developing relevant and immediately applicable skills. Establishing a network of $\mathrm{OH}$ providers could improve conditions for workers and companies, globally.

\section{OUTCOMES OF AN INNOVATIVE TRAIN-IN-PLACE OCCUPATIONAL MEDICINE RESIDENCY PROGRAM}

Judith Green-McKenzie*, Edward Emmett. University of Pennsylvania, Philadelphia, Pennsylvania, USA

\subsection{6/oemed-2018-ICOHabstracts.294}

Introduction Physicians making a mid-career change in specialty may find options for formal training limited. We describe a train-in-place program, with measureable outcomes, created to meet the challenge of training mid-career physicians desiring formal training in the field of Occupational Medicine. Our objective is to evaluate educational outcomes from a novel residency program for mid-career physicians seeking formal training and board certification in Occupational Medicine. Methods Physicians train-in-place at select Clinical Training Sites where they practice, participating in eighteen visits to Philadelphia over a two year period. Program components include competency-based training structured around Subject Area Rotations, mentored trainee projects and periodic auditing visits to the Clinical Training Sites by program faculty. The main outcome measures are achievement of Accreditation Council on Graduate Medical Education milestones and American College of Occupational and Environmental Medicine competencies, performance on the American College of Preventive Medicine examinations, diversity in selection and placement of residents after training, and the number of graduates who remain in the field.

Results Graduates, 113 to date, comprised 7.5\% of new American Board of Preventive Medicine diplomates over the past decade, score competitively on the certifying examination, achieve all milestones, express satisfaction with training, and are geographically dispersed representing every region of the United States. Most practice outside of the 25 largest Standard Metropolitan Statistical Areas. Over 95\% remain in the field.
Conclusions Training-in-place is an effective approach to provide mid-career physicians seeking comprehensive skills and Board certification in occupational medicine formal training, and may be adaptable to other fields.

\section{DEVELOPMENT AND VALIDATION OF THE JOB CRAFTING SCALE FOR UNIVERSITY STUDENTS}

U Hyrkkänen*, H Kuusisto, P Mäkilä. Turku University of Applied Sciences, Turku, Finland

\subsection{6/oemed-2018-ICOHabstracts.295}

Introduction The interest of the project 'Ready for Work' is in educating students to enhance occupational well-being in order that they will transfer the learnt to their future work. Job crafting was chosen as one concept that students should master. The first act was to assess the students' study related job crafting. For this the job crafting scale (Tims, et al 2012) required modifications. The aim of this paper is to present the job crafting scale modified for assessing the students' job crafting and its validation results.

Methods The modified scale consisted of 23 items, 8 items measuring dimension 'increasing structural job resources', 6 measuring 'increasing social job resources', 4 measuring 'increasing challenging demands' and 6 measuring 'decreasing hindering job demands'. 768 university students answered the questionnaire. The scale was tested by using reliability assessment and exploratory factory analysis.

Results The four dimensions each had good reliability. Cronbach alfas ranged $0.78-0.91$.

The four factors explained $56,6 \%$ of the variance. However the structure of four dimensions was not well supported. The first factor (Eigenvalue 7) explaining 35\% of the variance consisted of items measuring 'increasing social job resources'. The second factor (Eigenvalue 2,4) explaining 10\% of the variance was related to items of 'increasing structural job resources' as well as 'increasing challenging job demands'. The third factor (Eigenvalue 1,5) explaining 6,5\% of the variance consisted of items measuring 'decreasing hindering job demands'. The fourth factor explaining 5\% was related to a few items concerning the negotiation of the work to be done.

Conclusion The correspondence between students' work and employees' work needs deeper theoretical consideration when developing the scale for students' job crafting further. The scale items assessing job crafting factors 'increasing structural resources' and 'increasing challenging job demands' were related and this needs careful interpretation.

\section{OCCUPATIONAL HEALTH HISTORY TAKING ATTITUDES AND BEHAVIOURS OF CHIROPRACTIC INTERNS}

1,2D Madigan*, 2E Quinlan-Ruof, 1,2J Cambron, 'L Forst, 1J Zanoni, 'LS Friedman ${ }^{1}$ University of Illinois at Chicago, Chicago, USA; ${ }^{2}$ National University of Health Sciences, Lombard, USA

\subsection{6/oemed-2018-ICOHabstracts.296}

Introduction Occupational illness and injuries are a major health burden, with the large majority being musculoskeletal related. Because of this, health care providers, such as chiropractors, should understand the role of work in health conditions. This pilot study assessed the occupational history taking attitudes and behaviours of chiropractic interns for one year, 